Research Journal of Applied Sciences, Engineering and Technology 7(4): 875-891, 2014

DOI:10.19026/rjaset.7.330

ISSN: 2040-7459; e-ISSN: 2040-7467

(C) 2014 Maxwell Scientific Publication Corp.

Submitted: May 25, $2013 \quad$ Accepted: June 18, $2013 \quad$ Published: January 27, 2014

\title{
Research Article DTC-SVM Based on PI Torque and PI Flux Controllers to Achieve High Performance of Induction Motor
}

\author{
${ }^{1}$ Hassan Farhan Rashag, ${ }^{2}$ Nadia M.L. Tan, ${ }^{1}$ S.P. Koh, ${ }^{3}$ Ahmed N. Abdalla, ${ }^{1}$ K.H. Chong and ${ }^{1}$ S.K. Tiong \\ ${ }^{1}$ Department of Electronics and Communication Engineering, \\ ${ }^{2}$ Department of Electrical Power Engineering, Universiti Tenaga Nasional, Selangor, 43000, Malaysia \\ ${ }^{3}$ Faculty of Electrical and Electronic Eng., University Malaysia Pehang, Pekan 26600, Malaysia
}

\begin{abstract}
The fundamental idea of direct torque control of induction machines is investigated in order to emphasize the property produced by a given voltage vector on stator flux and torque variations. The proposed control system is based on Space Vector Modulation (SVM) of electrical machines, Improvement model reference adaptive system, real time of stator resistance and estimation of stator flux. The purpose of this control is to minimize electromagnetic torque and flux ripple and minimizing distortion of stator current. In this proposed method, PI torque and PI flux controller are designed to achieve estimated torque and flux with good tracking and fast response with reference torque and there is no steady state error. In addition, design of PI torque and PI flux controller are used to optimize voltages in d-q reference frame that applied to SVM. The simulation Results of proposed DTC-SVM have complete excellent performance in steady and transient states as compared with classical DTC-SVM.
\end{abstract}

Keywords: Direct torque control, induction motor, PI controller, space vector modulation

\section{INTRODUCTION}

Control in DTC is robust and fast torque response, no needs for coordinate transformation no requirements for PWM pulse generation and current regulators. However, DTC drive has the steady state ripples in torque, flux and stator currents. The pulsations in flux and torque affect the precision of speed estimation. It also results in higher acoustical noise and in harmonic losses. Earlier, to eliminate these disadvantages, many researchers projected multilevel inverters, but the number of power devices is higher, which subsequently increases costs. Another solution consists of using Space Vector Modulation (SVM) instead of improving the DTC look-up table. This solution needs however several motor parameters and increases the difficulty of the DTC algorithm. So, recently Artificial Intelligence based techniques have gained a wide attention in control applications.

Some of authors proposed an algorithm for rotor and stator resistance estimation (Esref et al., 2010). Over a wide range of speeds, the variations in a Squirrel-Cage Induction Motor (SCIM) is critical for the performance of sensor less control of SCIM. The issue with a single Extended Kalman Filter (EKF) based solution is addressed by their proposed method. In addition to precision limitations, a high number of parameters states are estimated with a limited number of inputs. They have implemented an $8^{\text {th }}$ order EKF and check its performance for the synchronized estimation of rotor and stator resistances. Their results indicated the accurate estimation is only concentrate the time and the superiority of the braided EKF approach to the $8^{\text {th }}$ order EKF in sensor less control of SCIMs. In EKF algorithm, the approximate value of the stator resistance is achieved because the stator resistance is nonlinear. Also, the stator windings are affected by current overflows. Then, the speed controller of the motor cannot be evaluated accurately. A single Phase Induction Motor Drive (SPIMD) with stator resistance tuning is proposed in Hechmi et al. (2011). In this method, measurement of stator currents contributes to the estimation of speed in the proposed method. A very simple identification algorithm using d-axis stator current error for identifying the stator resistance is proposed. The comparisons of their simulated results are done with $1.1 \mathrm{~kW}$ SPIMD setup. In this method, the stator resistance estimation is based on the tuning parameters. The tuning parameters are adjusted accurately to measure the stator currents. On the other hand, the stator current was not controlled properly. The stator resistance values are not estimated correctly, when the error was occurred. Others proposed a switching Extended Kalman Filter (EKF) technique for rotor and stator resistance estimation in speed sensor less control of IMs (Murat et al., 2007). For estimation and control schemes, high performance speed sensor less control of Induction Motors (IMs) are used in

\footnotetext{
Corresponding Author: Hassan Farhan Rashag, Department of Electronics and Communication Engineering, Universiti Tenaga
} Nasional, Selangor, 43000, Malaysia

This work is licensed under a Creative Commons Attribution 4.0 International License (URL: http://creativecommons.org/licenses/by/4.0/). 
grouping with speed sensor less Direct Vector Control (DVC). This method is based on the succeeding implementation of two EKF algorithms, by switching from one algorithm to another at every $\mathrm{n}$ sampling period. The required system performance decided the number of sampling periods, $n$. The switching EKF approach is provided a precise estimation of an increased number of parameters than would be possible with a single EKF algorithm. This technique can be used for multiple parameter estimation in a variety of control methods, which is confirmed by the results. The drawback of this method has some errors occurred during the sampling period, which is automatically affected the system performance. Whenever the switching frequency has increased or decreased, the rotor and stator resistance value was changed.

To achieve fast torque response over the entire speed range in high-performance drives, the mechanical speed feedback signal is needed. So, a closed-loop speed or position control in both scalar and vectorcontrolled drives requires a speed sensor. Speed estimation methods are being used to avoid the speed measurement set-up and commercial sensor less vectorcontrolled drives are already available. Speed estimation techniques are classified as slip calculation and direct synthesis from state equations. From the measurement of stator voltages and currents, a sensor less drive control of standard induction motors can estimate the rotor speed. The review of the speed estimation based DTC techniques are described as following them, Estimating the speed information of vector controlled asynchronous motor without sensors has been obtained with Artificial Neural Networks (ANN) (Yuksel and Mehmet, 2011). High dynamic performance power semi conductors available from direct current motors can also be obtained from asynchronous motor through developments in Digital Signal Processors (DSP) and control techniques. The flux and moment can be controlled separately by using field diverting control in asynchronous motors. It is proved that, this method has the validity and high performance of the ANN speed estimator on real-time speed estimation. The drawback of this method is that the speed estimator is not directly controlled to the motor because it required vector control method. Also, the current values are not calculated properly and the starting current is increased to immeasurable level, therefore speed estimator is damaged. Design of speed estimation method of an induction motor using Elman Neural Networks (ENN) is proposed (Raja and Bayindi, 2003) in steady-state operation as well as transient operations under sudden load change and variable speed conditions. The proposed ENN-based speed estimator has been proved to be success, which replaced the speed sensor in vector control scheme. Efficiency and easy implementation are proved in their proposed technique. In this method have some drawbacks such as the problem of replacing speed sensor, loads and input parameters. Speed estimation based on Luenberger Observer (LO) by using measured and estimated stator currents and estimated stator flux is presented (Mabrouk et al., 2012) to achieve a good performance with computational difficulty reduction obtained by using the analytical relation to verify the LO gain matrix.. For current regulation, however, the proposed method is suggested a conventional Proportional-Integral (PI) controller with feed-forward compensation terms in the synchronous frame. The algorithm is simple and robust. The drawback of this method is that the estimation of stator current and rotor flux are calculated individually. The motor parameters are required to estimate the speed and the parameter estimation complexity is high. To achieve minimum flux ripple with constant inverter switching frequency, control algorithm is designed to provide separate control of the torque and flux (Vasudevan et al., 2006). This algorithm is much simpler and has less mathematical operations and can be implemented on most existing digital drive controllers comparing to the other DTC methods. Algorithm is based on imposing the flux vector spatial orientation and rotation speed, which defines the unique solution for reference stator voltage. This method is used to calculate the stator flux vector, torque and flux increments and to determined position of the stator flux vector. This method cannot be minimized the torque ripples properly due to the rotation speed undesired. So, torque and flux ripple minimization is dependent on the switching control frequency of the motor. Some researchers have presented a Direct Power Control (DPC) strategy for a Double Fed Induction Generator (DFIG) based wind energy generation system (Mohammad et al., 2010). From the optimal switching table, the estimated stator flux position and the errors of the active and reactive power Switching vectors for rotor side converter are selected. Undesired power and stator current ripple may be caused by few number of voltage vectors. In this method, the increased number of voltage vectors with application of the Discrete Space Vector Modulation (DSVM) is presented. Then, a new switching table in synchronous and sub synchronous frame is proposed. High efficiency and strength of the proposed control strategy during variations of active and reactive power, machine parameters and wind speed are established by DFIG system. In this method, the system measurement errors are specified at low speeds, so the motor efficiency is affected at high speed. Others have analyzed two different methods for Direct Torque Control (DTC) of induction motor fed from Current Source Inverter (CSI) (Aleksandar and Borislav, 2008). A well-known DTC strategy derived the first diverse method and developed for voltage inverter drives. That type of control basically used hysteresis type controllers for torque and flux. The inconvenience that aroused in such a drive was important torque pulsations due to the 
environment of CSI and occasional speed drops because of variable switching frequency. Based on constant switching frequency with modification of the inverter optimal switching table, the other DTC method is proposed. More improvements are reduced number of sensors as all the measurements were performed in DC link only and in flux estimator. Through the torque hysteresis comparator, the algorithm has proved with better performance without problems that exist in the similar drive. Ultimately, proposed system is simpler for execution in a real drive without rotational transformation and parameter dependences that is presented in vector control of the same drive. If the switching frequency value is increased automatically, then, the speed is varied uncontrolled level. Hence, the other speed control parameters (flux, torque, stator resistance and etc) are affected. Control law for induction motor drive based on a dynamic reconfiguration of a basic Direct Torque Control (DTC) algorithm associated to Space Vector Modulation (SVM-DTC) is activated to get the most excellent torque dynamic during transient states (Monmasson and Louis, 2003). The principle of reconfiguration concerned the condition of the machine. Subsequently, at steady-state, SVM-DTC algorithm is chosen since it allows reducing significantly the torque ripples. Moreover, an original and well-adapted modeling based on a polar representation of the state variables is also introduced. The drawback of the method is incorrect measurements at high speeds, so the torque of the motor is affected. Direct torque control is designed based on control of separation between amplitude and angle of reference stator flux to decrease the current distortion in steady-state condition by minimize electromagnetic torque ripple and stator flux droop (Yuttana et al., 2008). Besides, this proposed technique provided the easiness of a control system. In adjustment of the reference stator flux angle, the direct torque control is based on the relationship between instantaneous slip angular frequency and rotor angular frequency. At the rated value, the amplitude of the reference stator flux is always kept constant. The arrangement has been implemented to confirm its capability such as torque and stator flux responses, stator phase current distortion during dynamic and steady state with load variation. This method cannot be reduced the torque ripple and stator flux for desired solutions. Then the current distortion cannot be reduced properly. It has specified the system measurement errors at low speeds, but, in high speed errors are not considered. Torque ripple minimization algorithm is achieved by imposing the required stator voltage vector in each control cycle (Bo et al., 2009). In this method, $M$ and $T$ axial components of the stator voltage are achieved by measuring the stator flux error and the expected incremental value of the torque at every sampling time. The maximum angle rotation allowed is obtained. Investigational results showed that the proposed method combined with the Space Vector Pulse Width Modulation (SVPWM) could be implemented in most existing digital drive controllers and offering high performance in both steady and transient states of the induction drives at full speed range. The results showed that the torque fluctuation could not be eliminated by proper stator voltage. Moreover, the proposed scheme could maintain constant switching frequency for the inverter as well as solve the heating problem and current harmonics in the induction motor drives. A mixture of Direct Torque Control (DTC) and Space Vector Modulation (SVM) for an adjustable speed sensor less Induction Motor (IM) drive is proposed to reduce torque and flux ripple (Zhifeng et al., 2010). In this method, the inverter reference voltage is obtained based on input-output feedback linearization control using the IM model in the stator D-Q axes reference frame with stator current and flux vectors components as state variables. Moreover, a robust full-order adaptive stator flux observer is designed for a speed sensor less DTC-SVM system and a speed-adaptive law is given. Here, the strength of the observer systems is not ensured by designing the observer gain matrix based on state feedback $\mathrm{H} \infty$ control theory. Hence, it required more than two controllers for controlling the flux and torque control. Other researchers have projected a vector control strategy for direct torque controlled current source inverter fed induction motor drives. In this method, the inverter switching vector is selected based on angular position of stator flux, or rotor flux and the motor current vectors in the switching vector plane (Panneer Selvam et al., 2012). The control strategy allowed higher efficiency and the control loop gains reduced current and voltage phase error with torque ripple reduction comparison with other methods in their literature. The drive could easily operate in the four quadrants. The torque response of the drive was claimed to be comparable with that of a vector controlled drive. This method cannot be properly reduced the current and voltage error. Also, the angular position of stator flux or rotor flux is varied due to the uncontrolled switching signal. The switching description of an inverter feeding an induction motor controlled by the Direct Torque Control (DTC) technique is discussed (Bertoluzzo et al., 2005). Initially, the application share of the inverter voltage vectors for the stator flux casing half a sextant was distinct and predicted. The prediction is indicated that under operation at fixed inverter dc link voltage and stator flux magnitude, the application share is dependent only on the supply frequency of the motor and to a small extent on the load. The inverter transitions and the corresponding phase commutations within a stator flux sextant were analyzed. The inverter switching frequency is obtained by the outcome of the analysis that permits to calculate the commutations of 
the inverter phases in one turn of the stator flux. In addition, the Direct Torque Control (DTC) is discussed to produce fast response and robust control in an adjustable-speed drives (Lascu et al., 2004). In this method, a direct torque and flux control strategy based on variable-structure control and space-vector pulse width modulation is proposed for induction motor sensor less drives. The DTC transient merits and robustness are conserved and the steady-state behavior is improved by reducing the torque and flux pulsations. A dual reference frame motor model is introduced by a sliding-mode observer and is tested. The sensor less operation is suitable for only very low speed and the high speed application it is not suitable. The induction motor can be operated in the field weakening range due to the voltage limit of the inverter (Tripathi et al., 2006). In this method, current controllers are not used to achieve DTC by the expected direct torque control Space Vector Modulation (DTC-SVM) scheme. Control of the stator flux vector allowed for dynamic change in the torque in all regions, including field weakening with the six-step operation. This method described the torque control dynamic in the field weakening range using a step change in stator flux vector magnitude and its angular velocity. The voltage limiter is act as a voltage controller but the current controller is not used. So, the starting current of the motor is increased too high. The two main outputs, torque and flux amplitude are directly regulated by DTC by specific design of switching control strategies (Escobar et al., 2003).In this method, to design the switching sequence, a criterion in terms of the error and/or the prediction in one-step-ahead on these outputs is proposed. As a result, a control vector, i.e., the switch position is directly selected without the requirement of an auxiliary space vector or other modulation technique. Two criteria of quadratic and absolute value are considered. In this method, the vector controllers are designed improperly. To develop a low-cost but high performance IM drive, control scheme for the Direct Torque Control (DTC) of an Induction Motor (IM) is proposed, which used a single sensor of current inserted in the inverter dc link (Bertoluzzo et al., 2006). The scheme exploits a simple and robust algorithm to reconstruct the stator currents needed to estimate the motor flux and torque. This algorithm is operated in two stages: first, it predicts the stator currents from a model of the motor and then adjusts the prediction on the basis of the sensed dc-link current are given to demonstrate. The stator current of the motor is predicted by probability bases; so the flux and torque are not controlled accurately. Some researchers are presented a torque control scheme for high-performance induction machine drives to overcome some disadvantages of Direct Torque Control (DTC) (Jian et al., 2005). Here, Information about the rotor speed is not required for the improved DTC method in which the stator flux and the torque controllers use variablestructure control theory. Space vector modulation is applied to the voltage source inverter to reduce the torque, stator flux and current ripples. The fundamental modulation frequency is not considered so over modulation is occurred. Torque ripple reduction technique with constant switching frequency for Direct Torque Control (DTC) of an Induction Motor (IM) is designed (Abdelli et al., 2011). A minimum torque ripple control is enabled in this technique. A control technique for IM is proposed in order to obtain constant switching frequency and hence a torque ripples reduction. It consists of controlling directly the electromagnetic torque using a modulated hysteresis controller. The design methodology is based on Space Vector Modulation (SVM) of electrical machines with digital vector control. In static speed variation, the torque ripple is not able to minimize. An improved Direct Torque Control (DTC) method for sensor less matrix converter drives is presented which is characterized by minimal torque ripple, unity input power factor and good sensor less speed-control performance in the low-speed operation, while maintaining constant switching frequency and fast torque dynamics (Kyo-Beum and Blaabjerg, 2007). The advantages of matrix converters, DTC strategy using space-vector modulation and two PI controllers can be positively combined. An over modulation strategy and a simple nonlinearity-compensation method using transformation are also presented to overcome the degrading of dynamic torque response compared with the basic DTC method and the phase-current distortion due to the nonlinearity of the matrix converter. Proper PI controller tuning technique is not presented in nonlinearity case, the PI controller gains are cannot be tuned easily. An uncomplicated effective way to reduce the torque ripple for Direct Torque Control (DTC) of induction motor drives is proposed (Kuo-Kai et al., 2010). In this method, a global minimum torque ripple is provided by the proposed DTC which satisfies the root-mean-square (rms) criteria of torque ripple. The proposed global minimum torque ripple DTC is a twostep design. By the end of the control period, the first step drives the torque error to zero. The second step reduces the torque bias and rms ripple by modifying the unevenness switching patterns of the applied voltage vectors of the first step into proportionate ones. If the RMS values are not satisfied, then the torque ripple is not decreased. On the other hand, some researchers have presented a prediction scheme to diminish both the torque and flux ripples in a Direct Torque Control (DTC) induction motor drive (Beerten et al., 2010). The time hindrance associated with data processing results in additional torque and flux ripples in a discrete implementation of the classical DTC scheme. This fraction of the ripples could amount to a major portion of the overall ripple if the hysteresis bands are similar 
to the maximum torque and flux variations in one sampling interval. A prediction scheme with low computational difficulty and low parameter sensitivity is presented by them and both are compared to the standard DTC scheme. When the sampling frequency is raised, the prediction scheme could easily be extended to compensate for multiple time delays. However, the computation time remains unchanged. It requires more number of time delays, so the sampling frequency is raised and computation time is increased. To overcome the trouble of high torque ripple afflicting the conventional DTC technique, algorithm control based on switching table is proposed (Ambrozic et al., 2004). In this proposed technique, the switching table give the inverter voltage vector and applied for the time interval needed by the torque to reach the upper (or the lower) limit of the band, where the time interval is calculated from a suitable modeling of the torque dynamics. This method enables the control system emulating the operation of a torque hysteresis controller of analogy type as the application time of the inverter voltage vector was dictated by the allowed torque excursion and not by the sampling period. The drawback of this method is improper selection of voltage vector and the switching values are not measured correctly. Therefore, the incorrect values are not controlled the torque in an efficient way. Torque control scheme based on a Direct Torque Control (DTC) algorithm using a 12-sided polygonal voltage space vector for a variable speed control of an open-end induction motor drive is presented to choose the optimal switching vector for fast control of torque with small variation of stator flux within the hysteresis band (Patel et al., 2012). Here, a stator flux vector is used by the conventional DTC scheme for the sector identification and then the switching vector to control stator flux and torque. On the other hand, the proposed DTC scheme selects switching vectors based on the sector information of the estimated fundamental stator voltage vector and its relative position with respect to the stator flux vector. The synchronous frequency of function is derived from the computed stator flux using a low-pass filter technique. The fundamental stator voltage estimation is based on the steady-state model of IM. The planned DTC method utilizes the precise positions of the fundamental stator voltage vector and stator flux vector. Along with reduced switching frequency variation. In this control scheme, the full load torque control is not presented. Also, the switching frequency is approximately reduced.

The high frequency motor-drives such as Direct Torque Controlled (DTC) induction motor drives, the motor harmonic loss and electromagnetic interference are mostly affected by the spectrum of the motor input voltage. Comparing to classical pulse width modulated controlled drives, nonlinear elements in the control loop of DTC drive make harmonic analysis of the drive very complex. To overcome these problems, probabilistic method is proposed to study the harmonic contents of voltage in DTC of induction motors (Kaboli et al., 2006). An unsystematic process is used for the simulation of the DTC voltage chain. Then, the autocorrelation function of voltage vectors is calculated and its power spectrum density is obtained. The effect of flux and torque hysteresis controller bands, machine parameters and inverter dc-link voltage on the motor voltage spectrum is investigated. Specification of Major harmonics in the DTC voltage spectrum and their behaviors are described. The theoretical analysis is justified by presenting simulation and experimental results. In this method, the electromagnetic interference is mostly affected by the spectrum of the motor input voltage. So, the voltage vector measurements, the power density, the flux and torque of the motor are affected.

In this study, direct torque control with space vector modulation based on designing PI torque controller, PI flux controller, stator flux estimation and real time estimation of stator resistance is proposed to achieve torque and flux without ripple and high performance of induction motor.

\section{PROPOSED METHOD}

DTC-SVM based on Amplitude of stator voltage and stator flux angle: In DTC-SVM with close loop flux control, with close loop torque control and with close loop flux and torque control, the calculation of reference voltage vector is based on demanded $\Delta \lambda_{s}$. This differentiation algorithm is very sensitive to disturbances. In case of errors in the feedback signals, the differentiation algorithm may not be stable and this is very serious drawback of these methods that causes torque and flux ripple with deteriorate the performance of system. The proposed method DTC-SVM based on amplitude stator voltage and stator flux angle is used to modify the control system. In this method, the amplitude of stator voltage is controlled by PI torque and PI flux controller. The stator flux angle is controlled by rotor angular frequency and slip angular frequency. Figure 1 shows the block diagram of sensor DTC -SVM based on amplitude voltage and stator flux angle.

This control system is consist of PI controller for slip angular frequency, PI torque controller, PI flux controller and Cartesian to polar transformation block to calculate amplitude of stator voltage, while polar to Cartesian block is used to calculate stator voltages in direct and quadrature reference frame at next sampling time.

In this method, the PI speed controller is used to optimize the reference torque $\left(T_{r e f}\right)$ of the motor from the error between reference speed and the rotor speed $\left(w_{r e f}, w_{r}\right)$ respectively as: 


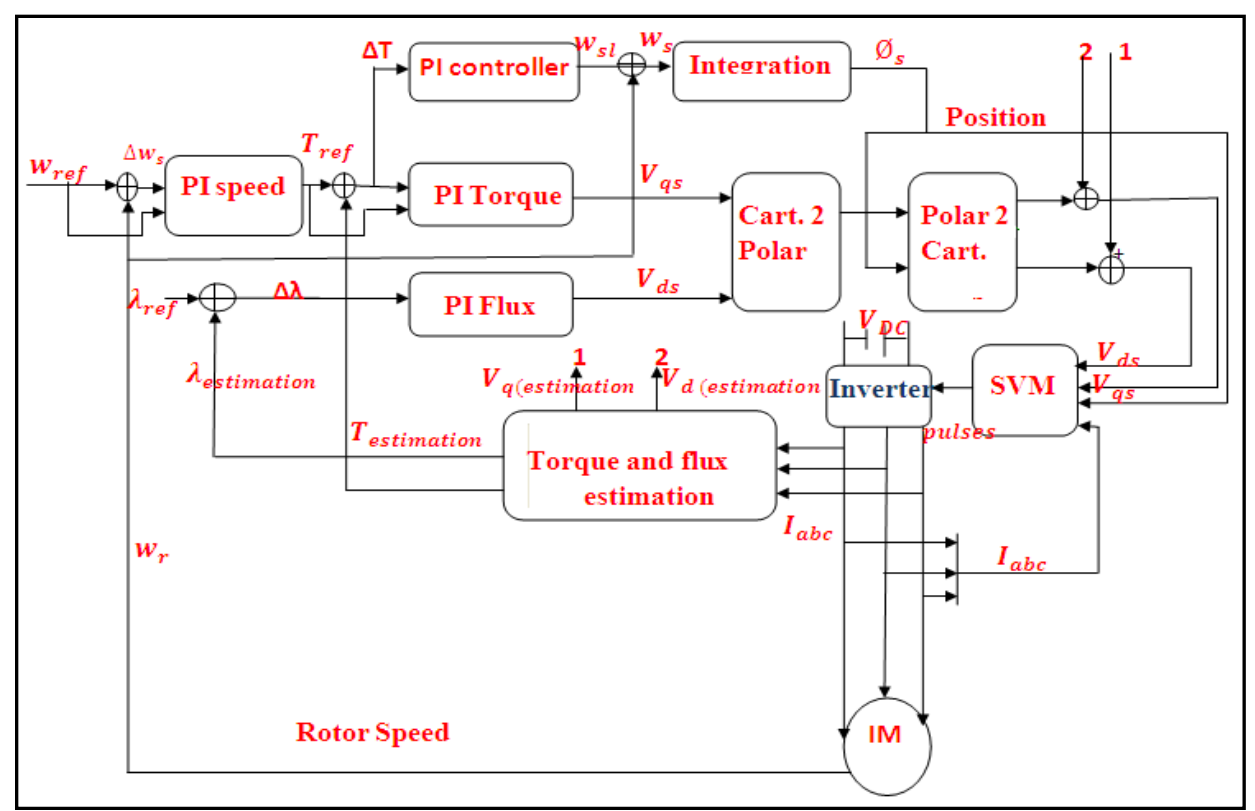

Fig. 1: Block diagram of proposed sensor DTC-SVM

$$
T_{r e f}=K_{p}\left[\Delta w+\frac{1}{T_{i}} \int \Delta w d t\right]
$$

where,

$$
\Delta w=w_{r e f}-w_{r}
$$

Then, the optimized torque is compared with the estimated torque to generate an error signal. This signal is the input of PI torque controller that computes the value of q- axis voltage. The output of PI torque controller can be expressed as:

$$
V_{s q}=K_{p}\left[\Delta T_{e}+\frac{1}{T_{i}} \int \Delta T_{e} d t\right]
$$

where,

$$
\Delta T_{e}=T_{\text {ref }}-T_{\text {estimation }}
$$

The reference flux is compared with estimated flux to generate error signal. The error signal is applied to the PI flux controller to compute the value of d-axis voltage. The d-axis voltage can be derived as:

$$
V_{s d}=K_{p}\left[\Delta \lambda+\frac{1}{T_{i}} \int \Delta \lambda d t\right]
$$

where, $\Delta \lambda=\lambda_{\text {ref }}-\lambda_{\text {estimation }}$

Based on Cartesian to polar block, these q and $\mathrm{d}$ axis voltages are converted into amplitude voltage. The output of Cartesian to polar can be expressed as:

$$
|V|=\sqrt{V_{s d}^{2}+V_{s q}^{2}}
$$

On the other hand, the error between reference torque and estimated torque is applied to PI controller to compute the value of instantaneous slip angular frequency $\left(w_{s l}\right)$ required to adjust stator flux angle. The PI controller for slip angular frequency can be expressed as:

$$
w_{s l}=K_{p}\left[\Delta T_{e}+\frac{1}{T_{i}} \int \Delta T_{e} d t\right]
$$

The stator angular frequency can be obtained by adding rotor angular frequency and slip angular frequency as:

$$
w_{s}=w_{r}+w_{s l}
$$

where, $\mathrm{w}_{\mathrm{s}}, \mathrm{w}_{\mathrm{r}}, \mathrm{w}_{\mathrm{sl}}$ are stator, rotor and slip angular frequency, respectively.

The stator flux angle is driven from integrating the stator angular frequency as:

$$
\theta_{s}=\int w_{s} d t
$$

Depending on the position of the stator flux and amplitude voltage, it is possible to switch on the suitable voltage vectors to control both flux and torque. By apply polar to Cartesian transformation block on both amplitude voltage and stator flux angle in Eq. (5) and (8) respectively, the direct and quadrature voltages can be expressed as follow:

$$
V_{s d}=|V| \cos \theta_{s}
$$




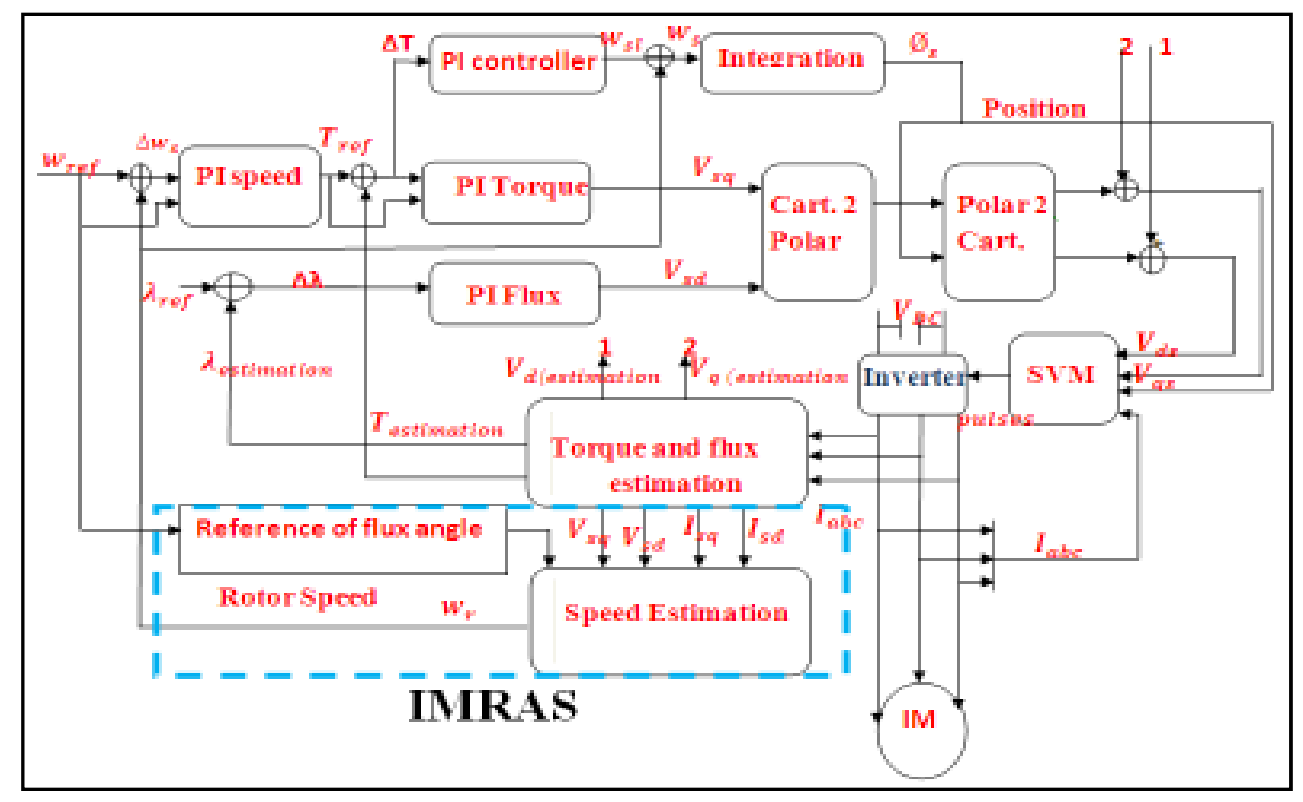

Fig. 2: Block diagram of proposed sensor less DTC-SVM

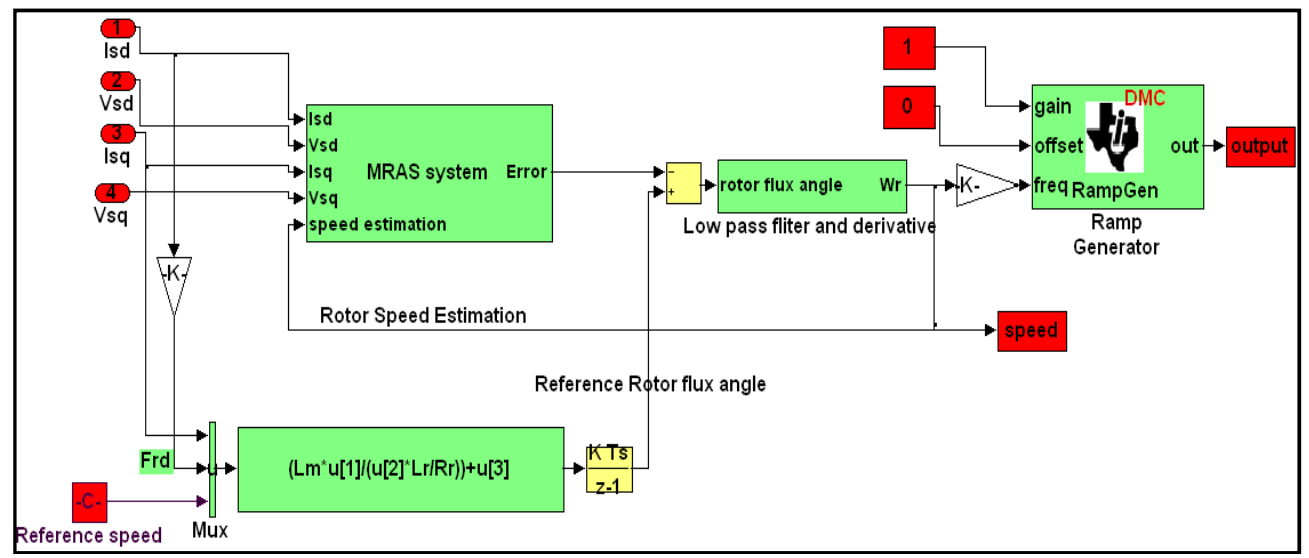

Fig. 3: Simulink implementation of IMRAS

$$
V_{s q}=|V| \sin \theta_{s}
$$

The error of stator voltage can be expressed as:

$$
\begin{aligned}
& \Delta V_{s d}=V_{s d}-V_{s d(\text { estimation })} \\
& \Delta V_{s q}=V_{s q}-V_{s q(\text { estimation })}
\end{aligned}
$$

Finally, the reference of stator voltages in d-q frames are calculated based on forcing the stator voltage error to zero at next sampling period. The next stator voltages are expressed as:

$$
\begin{aligned}
& V_{s d}(k+1)=\Delta V_{s d}(k)+R_{s} I_{s d}(k) \\
& V_{s q}(k+1)=\Delta V_{s q}(k)+R_{s} I_{s q}(k)
\end{aligned}
$$

By apply inverse park transformation on Eq. (13) and (14), the stator voltages in $\alpha$ and $\beta$ frame are generated and apply to SVM. From the output of SVM, the motor control signal is generated and the speed of the induction motor regulated toward the rated speed.

In sensor DTC-SVM based on amplitude voltage and stator flux angle, the encoder used for position and speed measurement may lead to problems. Losses of output information, offset, disturbances, measure deviation and channel mismatch may occur. Sensor less DTC-SVM of induction motor drives estimates position using an observer and eliminates the need for the speed sensor. It reduces hardware complexity, size, maintenance and ultimately cost. It also eliminates direct sensor wiring and has been shown to have better noise immunity and increased reliability. The block diagram of sensor less DTC-SVM based on 


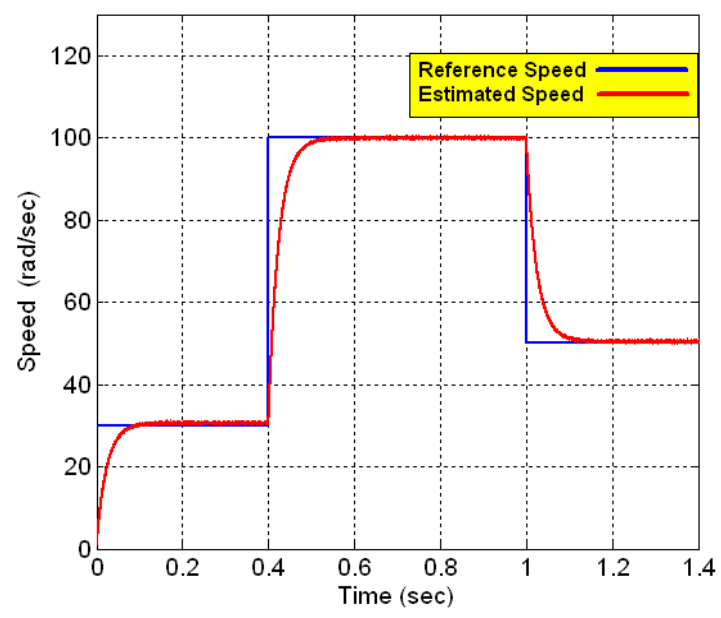

Fig. 4: Tracking of estimated speed with reference speed

Improvement Model Reference Adaptive System (IMRAS) is shown in Fig. 2.

- Improvement Model Reference Adaptive System (IMRAS): Model Reference Adaptive Systems (MRAS) are used to estimate quantities using a reference model and an adaptive model. In MRAS, PI controller is used to estimate rotor speed. However, the PI controller consumes time for tuning the proportional and integral gain to get desired estimated speed. Therefore, IMRAS is proposed to estimate the speed which cut down on tuning time and providing a good performance. IMRAS is based on reference speed, rotor flux and stator current without the need for PI controller

To compute the IMRAS, the reference full order model is calculated in the stator reference frame as:

$$
\begin{aligned}
& \lambda_{r d}=\frac{L_{r}}{L_{m}}\left[\left(\int V_{s d}-R_{s} I_{s d}\right) d t-\sigma L_{s} I_{s d}\right] \\
& \lambda_{r q}=\frac{L_{r}}{L_{m}}\left[\left(\int V_{s q}-R_{s} I_{s q}\right) d t-\sigma L_{s} I_{s q}\right]
\end{aligned}
$$

The adaptive full order model is calculated as:

$$
\begin{aligned}
& \lambda_{r d f}=\int\left[-\frac{L_{m}}{T_{r}} \psi_{r d f}-w_{r} \psi_{r q f}+\left(\frac{L_{m}}{T_{r}}\right) I_{s d}\right] d t \\
& \lambda_{r q f}=\int\left[-\frac{L_{m}}{T_{r}} \psi_{r q f}+w_{r} \psi_{r d f}+\left(\frac{L_{m}}{T_{r}}\right) I_{s q}\right] d t
\end{aligned}
$$

The error of two models is calculated as:

$$
e_{m}=\lambda_{r d} \lambda_{r q f}-\lambda_{r q} \lambda_{r d f}
$$

The reference of rotor flux angle is computed as:

$$
\theta_{r e f}=\int\left[\frac{L_{m} I_{s q}}{T_{r} \lambda_{r d}}+w_{r e f}\right] d t
$$

Figure 3 shows Simulink implementation of IMRAS. As shown in Fig. 4, this reference angle $\theta_{\text {ref }}$ is compared with the error $\left(e_{m}\right)$ of MRAS to generate estimated rotor flux angle. The estimated angle is passed through a low pass filter to have a smooth variation of rotor flux angle value. This signal is applied to the input of the derivative that computes the value of estimated speed $w_{\text {est }}$. The output of derivate can be expressed as:

$$
w_{e s t}=\frac{d}{d t}\left(\theta_{r e f}-e_{m}\right)
$$

This updated speed can be used directly in controller. To calculate the ramp output of rotor speed, the rotor speed is applied to ramp generator block as shown in Fig. 3. This ramp generator generates the ramp output from the slope of the ramp signal; DC offset in ramp signal and the frequency of the ramp signal (frequency) inputs.

The output of the ramp generator at sampling instant $k$ is governed by the following algorithm:

$$
\operatorname{out}(k)=\operatorname{angle}(k) * \operatorname{gain}(k)+\text { offset }(k)
$$

The angle $(k)$ is defined as:

$$
\begin{aligned}
& \operatorname{angle}(k)=\operatorname{angle}(k-1)+f r e q(k) * \\
& \text { Maximumstepangle }
\end{aligned}
$$

The maximum step angle determines the rate of the change of the output. Therefore, the frequency of the ramp output is controlled by a precision frequency generation algorithm. This ramp output is called also rotor position.

Figure 4 shows the simulation result of the reference and estimated speed in the proposed sensor less DTC-SVM when the reference speed has step change from $30 \mathrm{rad} / \mathrm{s}$ to $100 \mathrm{rad} / \mathrm{s}$ at $0.4 \mathrm{~s}$ and then from $100 \mathrm{rad} / \mathrm{s}$ to $50 \mathrm{rad} / \mathrm{s}$ at $\mathrm{t}=1 \mathrm{~s}$. Figure 5 show that the estimated speed could accurately track the change of the reference speed when speed reference has changed and have fast response. The proposed IMRAS system is relatively robust with respect to the change of the speed reference. Figure 5 shows that frequency of output ramp (rotor position) is very low at $30 \mathrm{rad} / \mathrm{sec}$ and very high at $100 \mathrm{rad} / \mathrm{sec}$. It can be noted that the frequency of ramp output increases with speed and is directly proportional to the rotor speed.

- Design of PI torque controller based on quadrature voltage $\left(\boldsymbol{V}_{\boldsymbol{s} q}\right)$ : From Fig. 1 and 2, the magnitude of torque control is performed based on amplitude of stator flux and rotor flux $\left(\lambda_{s}, \lambda_{r}\right)$. The electromagnetic torque control can be performed by controlling torque angle $(\delta)$ with constant amplitude of stator and rotor flux. When 


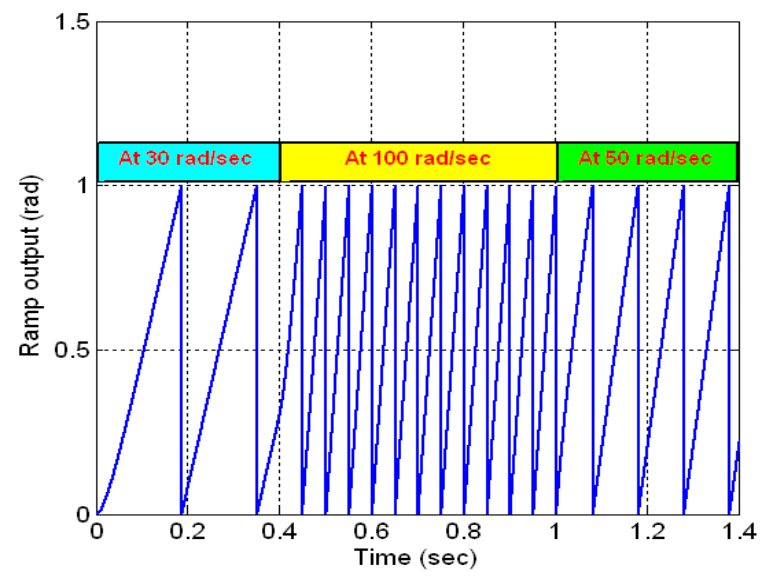

Fig. 5: Ramp output at different speeds

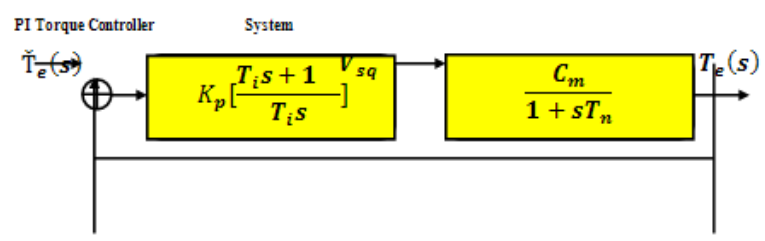

Fig. 6: Block diagram of close loop PI torque controller

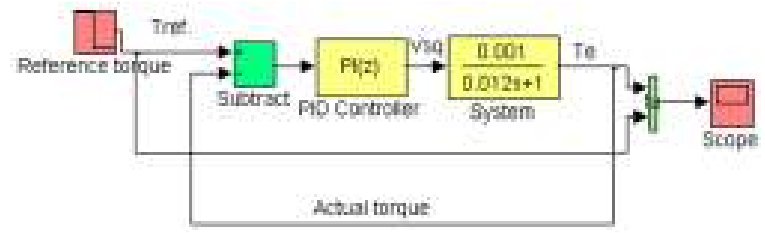

Fig. 7: Simulink model for auto tuning of PI torque controller

considering the rotor flux vector rotates after stator flux vector with torque angle, the stator and rotor flux vector can be represented in term of stator angular frequency and rotor angular frequency $\left(w_{s}, w_{r}\right)$ respectively. The position of both flux vectors rotating with angle $\left(\theta_{s}, \theta_{r}\right)$ with respect to real axis in the stationary reference frame. The Eq. 2.88 can be rearranged as:

$$
\begin{aligned}
& T_{e}=\frac{3}{2}\left(\frac{P}{2}\right) \frac{L_{m}}{L_{s} L_{r} \sigma}\left|\lambda_{r}\right|\left|\lambda_{s}\right| e^{j w_{s} t} e^{j w_{r} t} \\
& T_{e}(t)=\frac{3 P}{2} \frac{L_{m}^{2}}{R_{r} L_{s}^{2}}|\lambda|^{2}\left[1-e^{-t / T_{n}}\right] w_{s l}
\end{aligned}
$$

The slip angular frequency can be derived as:

$$
w_{s l}=\frac{L_{m} L_{s}}{L_{s} T_{r} \lambda_{r d}} I_{s q}
$$

Since

$$
\left|\lambda_{r}\right|=\lambda_{r d} w_{s l}=\frac{L_{m} \lambda_{s q}}{L_{s} T_{r}\left|\lambda_{r}\right|}
$$

where, $T_{r}$ the rotor time constant.

Substitute Eq. (27) into Eq. (25) as:

$$
\begin{aligned}
& T_{e}(t)=\frac{3 P}{2} \frac{L_{m}^{2}}{R_{r} L_{s}^{2}}|\lambda|^{2}\left[1-e^{-t / T_{n}}\right] \frac{L_{m} \lambda_{s q}}{L_{s} T_{r}\left|\lambda_{r}\right|} \\
& T_{e}(t)=\frac{3 P}{2} \frac{L_{m}^{3}}{\left|\lambda_{r}\right| T_{r} R_{r} L_{s}^{3}}|\lambda|^{2}\left[1-e^{-t / T_{n}}\right] \lambda_{s q}
\end{aligned}
$$

The Eq. (29) shows the relationship between electromagnetic torques with quadrature stator flux vector. If the term $\left(R_{S} I_{s}\right)$ can be neglected in the particular for high speed operation, the extremity of stator flux vector $\left(\lambda_{s q}\right)$ moves in the same direction of voltage vector $\left(V_{s q}\right)$. Thus the amplitude of stator flux and angle $\left(\theta_{s}\right)$ can be simultaneously adjusted by moving of the voltage vector $\left(V_{s q}\right)$. Therefore, Eq. (29) can be written as:

$$
T_{e}(t)=\frac{3 P}{2} \frac{T_{s} L_{m}^{3}}{\left|\lambda_{r}\right| T_{r} R_{r} L_{s}^{3}}|\lambda|^{2}\left[1-e^{-t / T_{n}}\right] V_{s q}
$$

where, $T_{s}, T_{r}$ are the sampling time and rotor time constant, respectively, $c_{m}=\frac{3 P}{2} \frac{T_{S} L_{m}^{3}}{\left|\lambda_{r}\right| T_{r} R_{r} L_{S}^{3}}|\lambda|^{2}$ is constant and equal to (0.001), $T_{n}=\sigma T_{r}=0.012$

From above equation, the relationship between torque and quadrature voltage is quite clear. The dynamic torque response depends on quadrature axis voltage. By taking Laplace in the Eq. (30) as:

$$
T_{e}(s)=\frac{0.001}{1+0.012 s} V_{s q}(s)
$$

The block diagram of close loop PI torque controller is shown in Fig. 6.

The closed loop transfer function of torque control can be expressed as:

$$
\begin{aligned}
& \frac{T_{e}(s)}{\check{\mathrm{T}}_{e}(s)}=\frac{\frac{0.001}{1+0.012 s}\left[K_{p} \frac{T_{i} s+1}{T_{i} s}\right]}{1+\frac{0.001}{1+0.012 s}\left[K_{p} \frac{T_{i} s+1}{T_{i} s}\right]} \\
& \frac{T_{e}}{\check{\mathrm{T}}_{e}}=\frac{0.001 s K_{p} T_{i}+0.001 K_{p}}{0.012 s^{2} T_{i}+T_{i} s+0.001 s K_{p} T_{i}+0.001 K_{p}}
\end{aligned}
$$

The parameters of PI torque controller $\left(k_{p}, k_{i}\right)$ can be calculated in Simulink by auto tuning of PI controller depends upon transfer function of torque controller as shown in Fig. 7.

In simulink, the torque reference is $5 \mathrm{Nm}$ and sampling time is $50 \mu \mathrm{s}$. The value of PI controller parameters based on auto tuning are $0.897,20063.7$ for proportional and integral gain respectively. Simulation results confirm proper operation of the PI torque controller. The symmetric optimum criterion can be applied to tune torque controller in analyzed DTC-SVM 


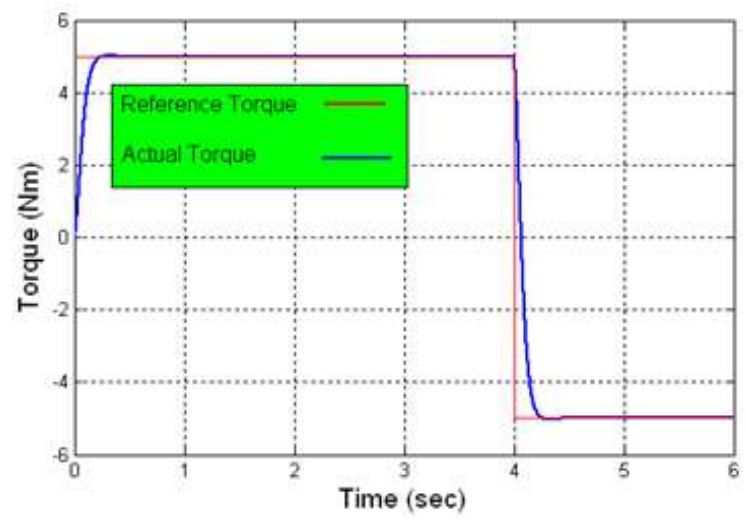

Fig. 8: Torque performance of torque controller design

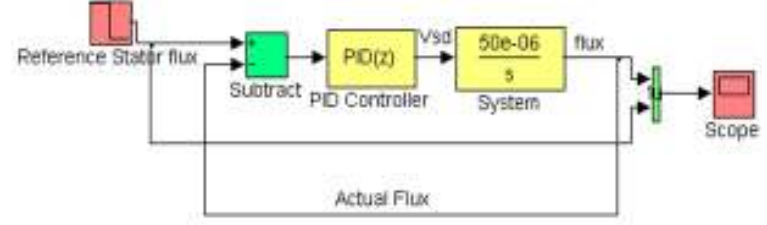

Fig. 9: Simulink model for auto tuning of PI flux controller

structure. Figure 8 shows good tracking with fast response by actual torque with reference torque and there is no steady state error.

Additional assumption for the torque controller analysis is that the stator flux magnitude is constant. Therefore, decoupling between flux and torque control loops is important.

- Design of PI flux controller based on direct voltage $\left(\left(\boldsymbol{V}_{\boldsymbol{s}}\right)\right.$ : From Fig. 1 , the relationship between output of PI flux controller $\left(V_{s d}\right)$ and the magnitude of stator flux estimation $\left(\lambda_{\text {est }}\right)$ can be expressed as shown below.

The output value of stator flux in stator flux estimation is expressed as:

$$
\lambda_{s}=\left|\lambda_{s}\right| e^{j \emptyset_{s}}
$$

where,

$$
\begin{aligned}
& \lambda_{e s t}=\left|\lambda_{s}\right| \\
& \left|\lambda_{s}\right|=\lambda_{s} e^{-j \emptyset_{s}(t)} \\
& \left|\lambda_{s}\right|=\lambda_{s}\left(\cos \emptyset_{s}-j \sin \emptyset_{s}\right)
\end{aligned}
$$

By using Laplace transform:

$$
\begin{aligned}
& \left|\lambda_{s}\right|=\lambda_{s}\left[\frac{s}{s^{2}+\emptyset_{s}^{2}}-j \frac{\emptyset_{s}}{s^{2}+\emptyset_{s}^{2}}\right] \\
& \emptyset_{s}=w_{s} * T_{s} \cong 0
\end{aligned}
$$

$$
\left|\lambda_{s}\right|=\lambda_{s} \frac{1}{s}
$$

The stator flux consists of the real and imaginary parts and can be expressed as:

$$
\lambda_{s}=\lambda_{s d}+j \lambda_{s q}
$$

Substitution Eq. (40) into Eq. (39):

$$
\left|\lambda_{s}\right|=\left(\lambda_{s d}+j \lambda_{s q}\right) \frac{1}{s}
$$

Separate the real and imaginary parts in Eq. (41):

$$
\left|\lambda_{s}\right|=\lambda_{s d} \frac{1}{s}, 0=j \lambda_{s q} \frac{1}{s}
$$

The stator flux in direct reference frame can be written in terms of stator voltage and current as:

$$
\begin{aligned}
& \lambda_{s d}=\left(V_{s d}-I_{s d} * R_{s}\right) * T_{s} \\
& \lambda_{s d}=\left(V_{s d}-\frac{\lambda_{r d}}{L_{m}} * R_{s}\right) * T_{s}
\end{aligned}
$$

Suppose that $\frac{\lambda_{r d}}{L_{m}} * R_{s} * T_{s} \cong 0$

$$
\left|\lambda_{s}\right|=\frac{V_{s d^{*} T_{s}}}{s}
$$

The relationship between output of PI flux controller $\left(V_{s d}\right)$ and the magnitude of stator flux estimation $\left(\lambda_{e s t}\right)$ as:

$$
\frac{\left|\lambda_{e s t}\right|}{V_{s d}}=\frac{T_{s}}{s}
$$

The close loop transfer function between magnitude of stator flux estimation $\left|\lambda_{\text {est }}\right|$ and reference of stator flux $\left|\lambda_{\text {sref }}\right|$ is:

$$
\frac{\left|\lambda_{\text {est }}\right|}{\left|\lambda_{\text {sref }}\right|}=\frac{k_{p} T_{S} S+T_{S} k_{i}}{S^{2}+k_{p} T_{S} S+T_{s} k_{i}}
$$

The parameters of PI controller can be computed by auto tuning based on Simulink of flux control loop as shown in Fig. 8.

In Fig. 9, the reference flux and sampling time are $0.96 \mathrm{wb}$ and $50 \mu \mathrm{s}$ respectively. The values of proportional and integral gain after tuning are 223400 and 119979, respectively. From Fig. 10, it can be said that the desired response time of actual flux is achieved and the flux tracks the reference well without steady state error. This strongly confirms the capability of the proposed flux control design for proper operation in the steady state and can be applied to tune flux controller in analyzed DTC-SVM structure. 


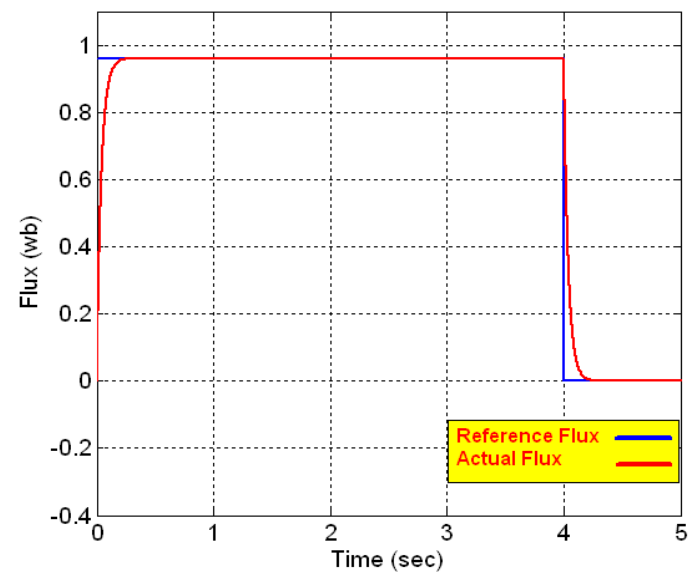

Fig.10: Flux performance of the flux control design

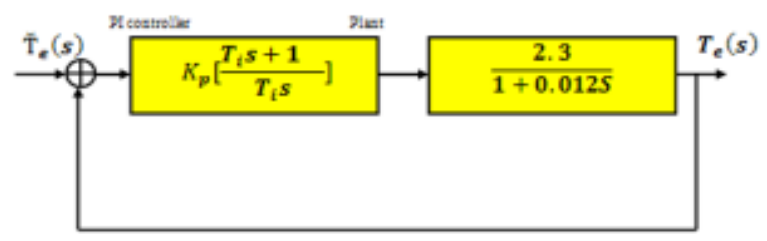

Fig. 11: Block diagram of close loop of slip angular frequency

In addition, from Eq. (25), the relationship between electromagnetic torque and slip angular frequency is quite clear. The slip angular frequency is adjusted by PI controller based on torque error. Also, slip angular frequency is used to adjust stator flux angle. The parameters of PI controller can be calculated as the same method for auto tuning of PI torque and PI flux controller. The block diagram of close loop slip angular frequency based on PI controller is shown in Fig. 11.

Also, the dynamic of torque response depends on slip angular frequency and can be expressed as:

$$
\mathrm{T}_{\mathrm{e}}(\mathrm{s})=\frac{2.3}{1+0.012 \mathrm{~s}} \mathrm{w}_{\mathrm{sl}}(\mathrm{s})
$$

After auto tuning of PI controller with close loop, the value of proportional and integral gain are 1.2 and 50 , respectively.

Real Time Estimation of Stator Resistance (RTESR): The variation of stator resistance due to changes in temperature or frequency degrades the performance of this control strategy and therefore is a big issue of DTC. The DTC-SVM become unstable if the stator resistance value used in the stator flux estimator differs from that of the actual machine resistance. In DTC drive, the stator flux is estimated by integrating the difference between the input voltage and the voltage drop across the stator resistance. Among the other variables of the machine, the stator flux vector is highly affected by the resistance changes particularly at low speed. As the resistance value varies by temperature, a mismatch between actual and estimated stator resistance occurs which can deteriorate the performance of DTC drives to some different extent. For instance, in the case of higher actual resistance values (caused by higher temperature), the produced effects might just be restricted to worsened stator flux response and higher copper losses resulted from higher stator current values. However, it should be noted that these effects could become more severe depend on torque limit assigned by speed controller, as even an inappropriate choice of these values could make the drive to become unstable for such a resistance variations. On the other hand, for the actual resistance smaller than the estimated one (cold environments), the unstable condition usually occurs. In fact, this in stability is caused by large voltage vectors chosen based on wrong stat or flux and torque error values. The estimation of stator resistance is essential to overcome instability and to guarantee a linear torque amplifier in the DTC drive.

To overcome this problem, the proposed method of real time estimation of stator resistance is based on stator voltage and stator current in d-q reference frame. An analytical procedure to estimate stator resistance is presented in the following.

The amplitude of stator voltage in d-q reference frame can be expressed as:

$$
\left|V_{s}\right|=\sqrt{V_{s d}^{2}+V_{s q}^{2}}
$$

The amplitude of stator flux in d-q reference frame is depicted as:

$$
\left|\lambda_{s}\right|=\sqrt{\lambda_{s d}^{2}+\lambda_{s q}^{2}}
$$

The stator voltages in $\mathrm{d}-\mathrm{q}$ reference frame can be combined to give:

$$
\begin{aligned}
& \left(\mathrm{V}_{\mathrm{sd}}^{2}+\mathrm{V}_{\mathrm{sq}}^{2}\right)=\mathrm{R}_{\mathrm{s}}^{2}\left(\mathrm{I}_{\mathrm{sd}}^{2}+\mathrm{I}_{\mathrm{sq}}^{2}\right)+2 \mathrm{w}_{\mathrm{s}} \mathrm{R}_{\mathrm{s}}\left(\lambda_{\mathrm{sd}} \mathrm{I}_{\mathrm{sq}}+\right. \\
& \lambda \mathrm{sqI} \mathrm{Isd}+\mathrm{ws} 2(\lambda \mathrm{sd} 2+\lambda \mathrm{sq} 2) \\
& \left|\mathrm{V}_{\mathrm{s}}^{2}\right|=\mathrm{R}_{\mathrm{s}}^{2}\left|\mathrm{I}_{\mathrm{s}}^{2}\right|+3 \mathrm{w}_{\mathrm{s}} \mathrm{R}_{\mathrm{s}} \mathrm{T}_{\mathrm{e}}+\mathrm{w}_{\mathrm{s}}^{2}\left|\lambda_{\mathrm{s}}^{2}\right|
\end{aligned}
$$

The average of stator angular frequency is expressed as:

$$
w_{s}=-\frac{\left(V_{s}-I_{s} R_{s}\right)}{\left|\lambda_{s}^{2}\right|} j \lambda_{s}
$$

The stator flux $\left(\lambda_{\mathrm{sd}}, \lambda_{\mathrm{sq}}\right)$ is based on both stator and rotor current in $\mathrm{d}-\mathrm{q}$ reference frame. Therefore, from Fig. 12, the stationary to rotor reference frame current equations corresponding to the Park's Transformation under the assumption that the rotor 


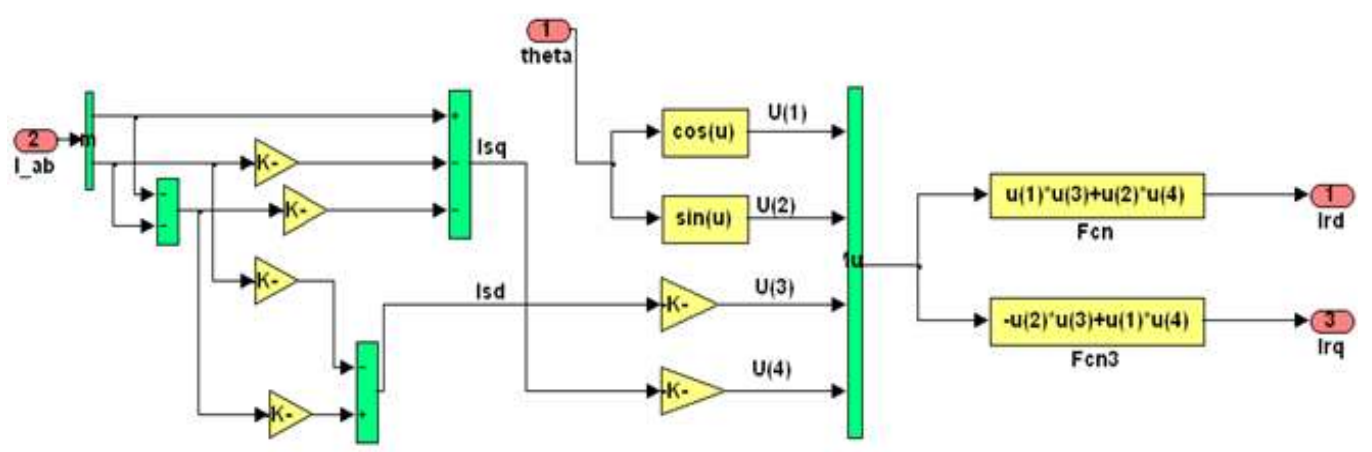

Fig. 12: Abc to stationary and stationary to dq rotor reference frame transformation block

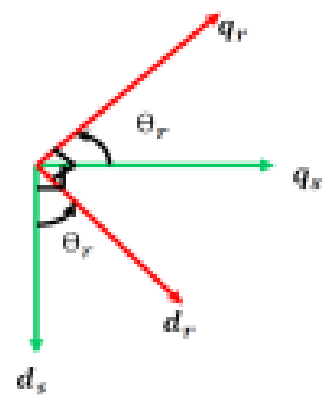

Fig. 13: Rotor reference frame and stationary reference frame coordinate representation

angle representation is chosen between the rotor q-axis and the stationary q-axis, as shown in Fig. 13, are given by:

$$
\begin{aligned}
& I_{r q}=I_{s q} \cos \theta_{r}-I_{s d} \sin \theta_{r} \\
& I_{r d}=I_{s q} \sin \theta_{r}+I_{s d} \cos \theta_{r}
\end{aligned}
$$

The coordinate representation of the stationary reference frame is shown in Fig. 13.

where, $\left(\theta_{r}\right)$ is the angle between stationary and rotating frame. $I_{r q}, I_{r d}$ are the rotor current in quadrature and direct reference frame.

From Eq. (52), the stator resistance estimation can be driven as:

$$
\mathrm{R}_{\mathrm{S}}=\frac{-3 \mathrm{w}_{\mathrm{S}} \mathrm{T}_{\mathrm{e}} \pm \sqrt{\left(3 \mathrm{w}_{\mathrm{s}} \mathrm{T}_{\mathrm{e}}\right)^{2}-4\left|\mathrm{I}_{S}^{2}\right|\left(\mathrm{w}_{S}^{2}\left|\lambda_{s}^{2}\right|-\left|\mathrm{v}_{S}^{2}\right|\right)}}{2\left|\mathrm{I}_{S}^{2}\right|}
$$

In order to minimize the problems of stator resistance variation to a very large extent, PI controller is used for compensating the change in the stator resistance. The change of stator resistance will change the amplitude of stator flux. The error of amplitude of stator flux and that of reference flux through PI controller will be used to minimize the change in stator resistance until the stator flux error becomes zero. Therefore, the steady state error of the resistance will be zero. The change of stator resistance can be expressed as:

$$
\Delta \mathrm{R}_{\mathrm{s}}=\Delta \lambda_{\mathrm{s}}\left(\mathrm{K}_{\mathrm{p}}+\int \mathrm{K}_{\mathrm{i}} \mathrm{dt}\right)
$$

where, $\Delta \lambda_{\mathrm{s}}=\lambda_{\text {ref }}-\lambda_{\text {estimation }}$

By combining Eq. (56) and (57), the optimized real time stator resistance estimation can be written as:

$$
\mathrm{R}_{\mathrm{so}}=\mathrm{R}_{\mathrm{s}}+\Delta \mathrm{R}_{\mathrm{s}}
$$

Figure 14 shows the block diagram of the proposed real time estimation of stator resistance. Figure 15 shows good tracking by the real time estimated stator resistance with actual resistance. There is no steady state error with high accuracy. The experimental result also show fast settling time and low steady state error at all range of speed) as is seen in Fig. 16.

The Fig. 15 shows the stator resistance simulation with short operation period. The serial communication interface output of the experimental result for $4 \mathrm{~s}$ is shown in Fig. 16. According to the computer simulation and experimental results shown above, the system shows fast response with higher accuracy.

Modified close loop stator flux estimation: The control algorithm in DTC-SVM methods are based on averaged values and the switching signals for the inverter which calculated by space vector modulator. DTC-SVM still encounter drawback at low speed which caused degrades the performance of whole system. One of the drawbacks is pure integration of stator flux estimation which caused saturation problems and dc drift. Stator flux estimation has an important effect on performance of direct torque control. Proposed method to counteract the drawback is close loop integration algorithm of stator flux estimation which is based on stator current, voltage model, voltage correction and low pass filter as shown in Fig. 17.

Rotor flux is derived from stator current in direct reference frame and can be written as:

$$
\lambda_{r d}=\left[l_{m} * I_{s d}\right] /\left(1+T_{r} . s\right)
$$




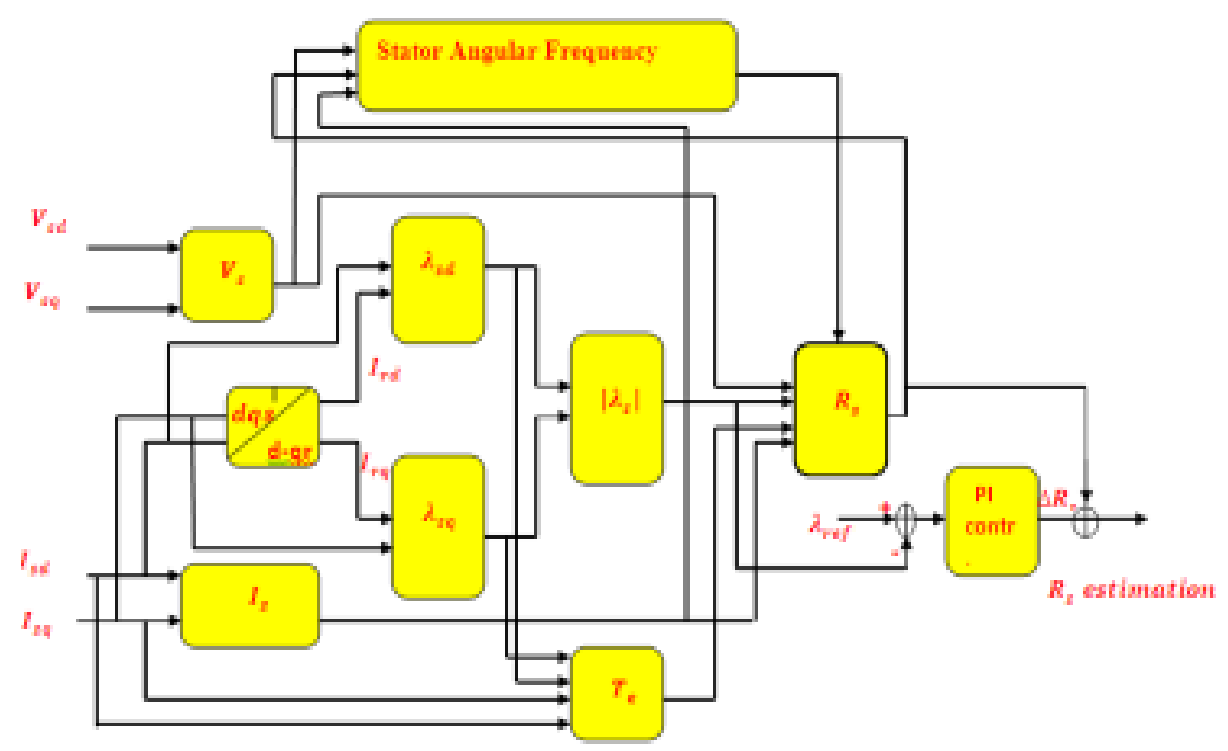

Fig. 14: Block diagram of proposed real time stator resistance estimation

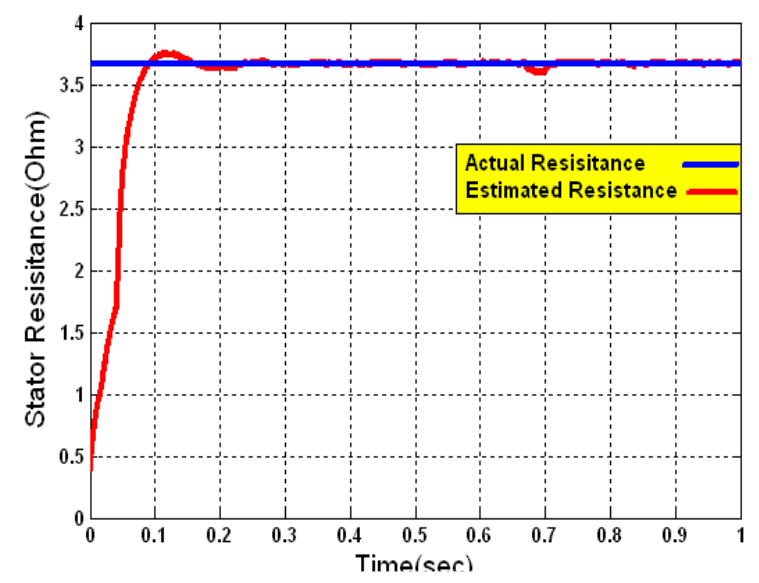

Fig.15: Simulation results of the stator resistance tracking the RTESR

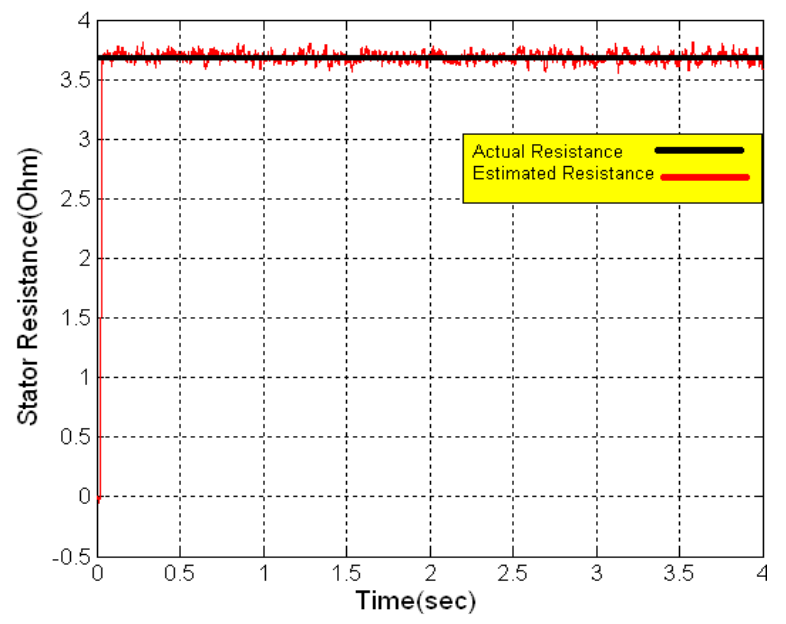

Fig. 16: Experimental results of the stator resistance tracking by the RTESR
The stator flux can be obtained from stator current and rotor flux as:

$$
\lambda_{s}=\left(\frac{L_{m}}{L_{r}}\right) \lambda_{r d}+\left(\left(L_{s} L_{r}-L_{m}^{2}\right) / L_{r}\right) I_{s d}
$$

Substitute Eq. (3.39) in to Eq. (3.40) as:

$$
\lambda_{s}=\left(\frac{L_{m}}{L_{r}}\right) \frac{\left[l_{m} * I_{s d}\right]}{1+T_{r} \cdot s}+\left(\left(L_{s} L_{r}-L_{m}^{2}\right) / L_{r}\right) I_{s d}
$$

The stator flux in Eq. (16) is compared with actual flux $\left(\lambda^{*}\right)$ to generate an error signal. This error is an input of PI controller that computes the value the correction voltage $\left(V_{c}\right)$. The output of PI controller can be expressed as:

$$
V_{\text {correct }}=\Delta \lambda_{s}\left(K_{p}+\frac{K_{i}}{s}\right)
$$

where, $\Delta \lambda_{s}=\lambda_{s}-\lambda^{*}$

The main purpose of correction voltage is to correct the value of estimated stator flux, to compensate for the error associated with pure integrator and stator resistance measurement at low speed and to provide a wide speed range operation

The estimated stator flux in direct reference frame is given by:

$$
\lambda_{s d}=\frac{\left[V_{s d}-V_{\text {correct }}-I_{s d} * R_{S}\right]}{\left(s+w_{c}\right)} *\left[w_{c} * T_{s}\right]
$$

where, $\frac{1}{s+w_{c}}$ is the integrator with low pass filter, $\left(w_{c}\right)$ is cutoff frequency and $T_{s}$ is sampling time.

The aim of replacing pure integrator with low pass filter is to avoid the problem saturation and integration drift due to the DC offsets present in the sensed currents or voltages. However, LPF introduces the phase and 


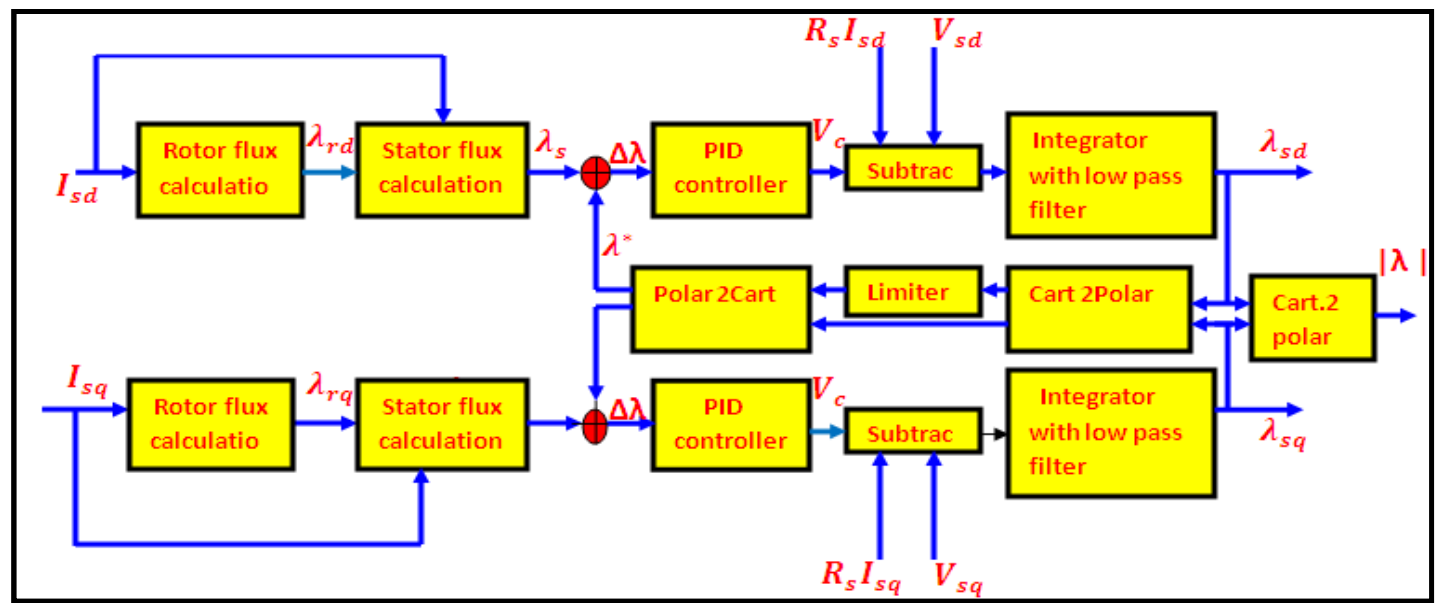

Fig. 17: Block diagram of proposed stator flux estimation

magnitude errors of stator flux estimation which affect on the selection of voltages vector and electromagnetic torque response and deteriorate the performance of DTC drive. To overcome the LPF problems, close loop of stator flux estimation is proposed. In this method, stator flux is transformed to amplitude and angle through a Cartesian to polar block. The magnitude of stator flux is a de signal and so is the limiter output. The flux magnitude and angle can be transformed back to Cartesian coordinates through a polar to Cartesian transform block, whose outputs are sinusoidal waveforms with limited amplitude without distortion, resulting in an improved performance of this modified integrator. On the other hand, the limiter value should be equal to stator flux reference. The cutoff frequency and sampling time have been used in Eq. (63) to limit the phase difference between the actual stator flux and the estimated stator flux.

It is assumed in this proposed method that the cut off frequency used in the LPF is $(20 \mathrm{rad} / \mathrm{sec})$ and induction motor is running under steady state.

By substituting Eq. (62) into Eq. (63), the output $\lambda_{s d}(s)$ of the controller is obtained by Laplace transform of Eq. (63) and can be written:

$$
\begin{aligned}
& \lambda_{s d}(s)=\frac{\left[V_{s d}(s)-I_{s d}(s) * R_{s}\right]+\left[\lambda_{s}(s)-\lambda^{*}(s)\right]\left(K_{p}+\frac{K_{i}}{s}\right)}{(s+20)} * \\
& {\left[w_{c} * T_{s}\right]}
\end{aligned}
$$

The estimated stator flux component is calculated by:

$$
s \lambda_{s d}(s)=\left[V_{s d}(s)-I_{s d}(s) * R_{s}\right.
$$

Substitution the relation above in the Eq. (64):

$$
\begin{aligned}
& \lambda_{s d}(s)\left(\left(s^{2}+20 s\right)\right)-w_{c} * T_{s} \lambda_{s d}(s) s^{2}= \\
& {\left[\lambda_{s}(s)-\lambda^{*}(s)\right]\left(K_{p} s+k_{i}\right) T_{s} * w_{c}}
\end{aligned}
$$

Since $w_{c} * T_{s}=50 \mathrm{e}-06 * 20$, therefore $\left(w_{c} *\right.$ $T_{s} \lambda_{s d}(s) s^{2} \cong 0$ )and the Eq. (66) can be written as:

$$
\begin{aligned}
& \lambda_{s d}(s)\left(\left(s^{2}+20 s\right)\right)=\left[\lambda_{s}(s)-\lambda^{*}(s)\right]\left(K_{p} s+\right. \\
& \left.k_{i}\right) T_{s} * w_{c}
\end{aligned}
$$

In Eq. (67), the stator flux $\lambda^{*}(s)$ is the output of polar to Cartesian and can be expressed as:

$$
\lambda^{*}(s)=|L| \frac{\lambda_{s d}}{\sqrt{\lambda_{s d^{2}+\lambda_{s q}{ }^{2}}}}
$$

From Eq. (68), the output of limiter $|L|$ is equal to the flux amplitude $\sqrt{\lambda_{s d}{ }^{2}+\lambda_{s q}{ }^{2}}$ when the flux amplitude is less than limiter value. Also, the output of limiter $|L|$ is equal to limier value when $\sqrt{\lambda_{s d}{ }^{2}+\lambda_{s q}{ }^{2}}$ is greater than limiter value. Therefore, the stator flux $\lambda^{*}(s)$ is approximately equal to $\lambda_{s d}$. The Eq. (67) can be expressed as:

$$
\begin{aligned}
& \lambda_{s d}(s)\left(\left(s^{2}+20 s\right)\right)=\left[\lambda_{s}(s)-\lambda_{s d}(s)\right]\left(K_{p} s+\right. \\
& \text { kiTs*wc }
\end{aligned}
$$

The close loop transfer function of stator flux estimation in d-reference frame can be expressed as:

$$
\frac{\lambda_{s d}(s)}{\left[\lambda_{s}(s)\right]}=\frac{\left(K_{p} s+k_{i}\right) k}{s^{2}+s\left(20+k_{p} k\right)+k * k_{i}}
$$

From Eq. (70), the block diagram of close loop of stator flux estimation in direct axis is shown in Fig. 18.

From the same method above, the close loop transfer function of stator flux in quadrature reference frame can be written as:

$$
\frac{\lambda_{s q}(s)}{\left[\lambda_{s}(s)\right]}=\frac{\left(K_{p} s+k_{i}\right) k}{s^{2}+s\left(20+k_{p} k\right)+k * k_{i}}
$$

The parameters of PID controller can be calculate either by using discrete PID controller for auto tuning 


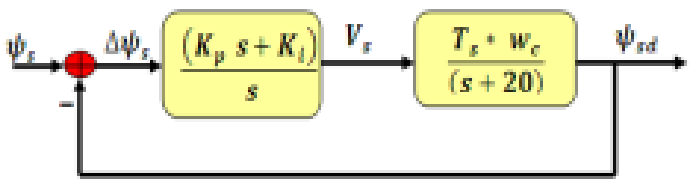

Fig. 18: Block diagram of close loop of stator flux estimation control loop

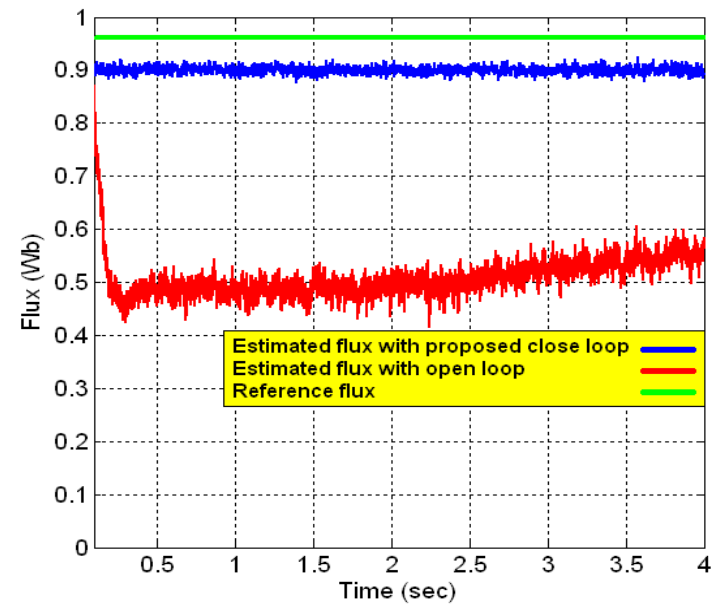

Fig. 19: Comparisons performance of stator flux estimation

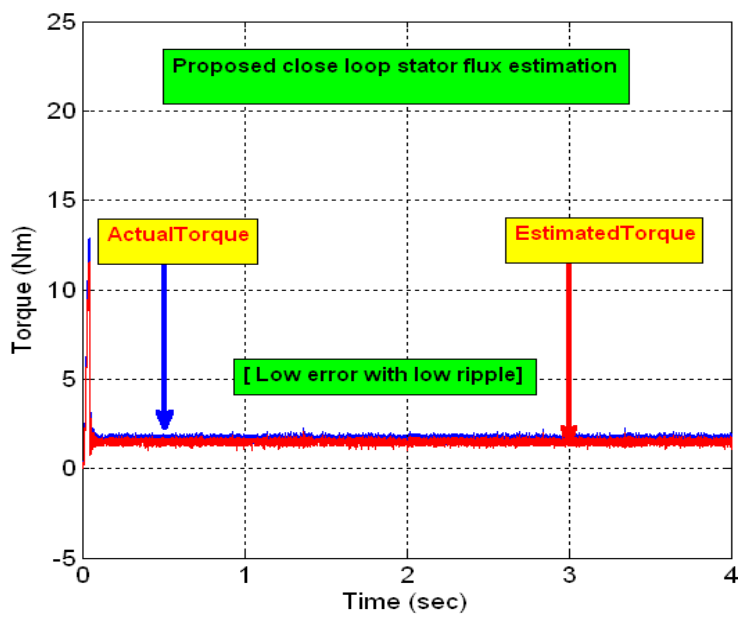

Fig. 20: Torque estimation of proposed DTC-SVM with close loop stator flux estimation

in Fig. 18 till get desired output by Simu link Matlab or by the following method.

The polynomial equation of a second order system is given by:

$$
\begin{aligned}
& s^{2}+2 \xi w_{n} s+w_{n}^{2}=0 \\
& w_{n}=\sqrt{k * k_{i}} \\
& 2 \xi w_{n}=20+k_{p} k
\end{aligned}
$$

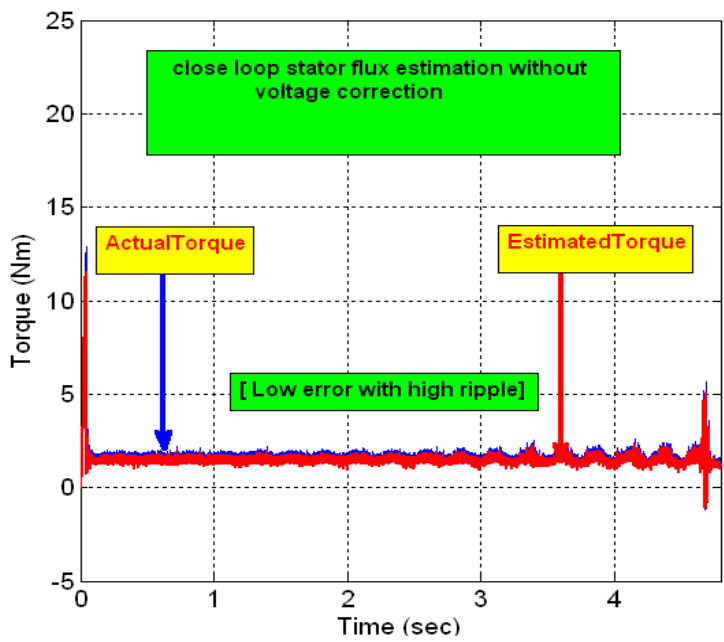

Fig. 21: Torque estimation of proposed DTC-SVM based close loop stator flux estimation without voltage correction

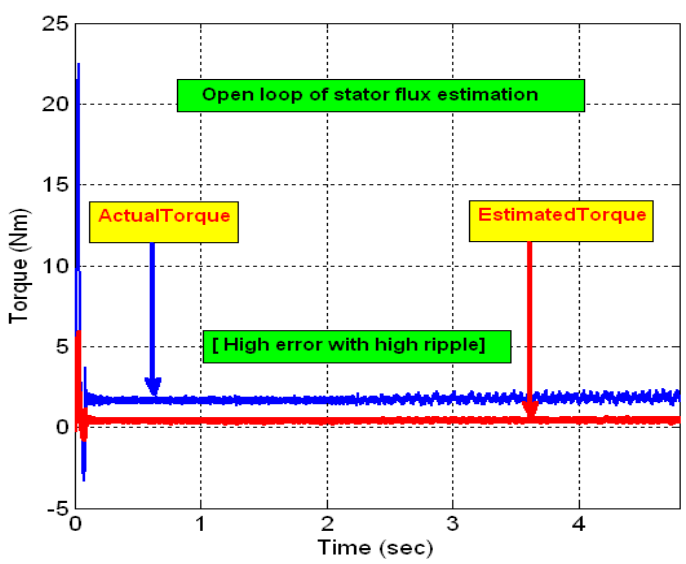

Fig. 22: Torque estimation of DTC-SVM with open loop stator flux estimation

$$
\xi=\frac{\left(20+k_{p} k\right)}{2 \sqrt{k * k_{i}}}
$$

The parameters of PI controller might be calculated as:

$$
\begin{aligned}
& k_{p}=\frac{\left(2 \xi w_{n}-20\right)}{k} \\
& k_{i}=\left[\frac{\left(w_{n} k_{p}\right)}{\left(2 \xi w_{n}-20\right)}\right]^{2}
\end{aligned}
$$

where, $w_{n}$ is the natural angular frequency and $\xi$ is the damping ratio.

\section{SIMULATION RESULTS}

In Fig. 19, the stator flux estimation in proposed method is approximately equal to reference flux with very low ripple as compared with DTC-SVM. 
Figure 20 to 22 shows the estimation torque response of the proposed DTC-SVM based on close loop stator flux estimation, close loop stator flux estimation without voltage correction and open loop stator flux estimation, respectively. In Fig. 20, the actual torque and estimated torque are almost equal and torque ripples are dramatically reduced.

\section{CONCLUSION}

This proposed method describes the performance of Direct Torque Control (DTC) based on space vector modulation, improvement model reference system, real time estimation of stator resistance and stator flux estimation. In this system, voltage feeding SVM is more stability because it relies on output voltages from two PI controllers. Depending on the position of the stator flux, it is possible to switch on the suitable voltage vectors to control both flux and torque. The proposed method of DTC-SCM show good performance of torque and flux without ripple as compared with other methods.

\section{REFERENCES}

Abdelli, R., D. Rekioua and T. Rekioua, 2011. Performances improvements and torque ripple minimization for VSI fed induction machine with direct control torque. ISA Trans., 50(2): 213-219.

Aleksandar, N. and J. Borislav, 2008. Different methods for direct torque control of induction motor fed from current source inverter. J. WSEAS Trans. Circuits Syst., 7(7): 738-748.

Ambrozic, V., G.S. Buja and R. Menis, 2004. Bandconstrained technique for direct torque control of induction motor. IEEE T. Ind. Electron., 51(4): 776-784.

Beerten, J., J. Verveckken and J. Driesen, 2010. Predictive direct torque control for flux and torque ripple reduction. IEEE T. Ind. Electron., 57(1): 404-412.

Bertoluzzo, M., G.S. Buja and R. Menis, 2005. An assessment of the inverter switching characteristics in DTC induction motor drives. IEEE T. Power Electr., 20(2): 457-465.

Bertoluzzo, M., G. Buja and R. Menis, 2006. Direct torque control of an induction motor using a single current sensor. IEEE T. Ind. Electron., 53(3): 778784.

Bo, L., G. Gui-Fang, H. Xiao-Hong and L. Xiao-Ning, 2009. Novel torque ripple minimization algorithm for direct torque control of induction motor drive. J. Shanghai Univ., 13(2): 155-163.

Escobar, G., A.M. Stankovic, E. Galvan, J.M. Carrasco and R. Ortega, 2003. A family of switching control strategies for the reduction of torque ripple in DTC. IEEE T. Contr. Syst. T., 11(6): 933-939.
Esref, E.O., G. Metin and B. Seta, 2010. Simultaneous rotor and stator resistance estimation of squirrel cage induction machine with a single extended Kalman filter. Turk J. Electr. Eng. Comput. Sci., 18(5): 853-863.

Hechmi, B.A., J. Mohamed, B. Mohamed and G. Moncef, 2011. High performance sensorless speed vector control of SPIM drives with on-line stator resistance estimation. J. Simul. Model. Pract. Theory, 19(1): 271-282.

Jian, L., Y. Geng, H. Wang and X. Wenli, 2005. Implementation of direct torque control scheme for induction machines with variable structure controllers. Tsinghua Sci. Technol., 10(5): 593597.

Kaboli, S., E. Vahdati-Khajeh and M.R. Zolghadri, 2006. Probabilistic voltage harmonic analysis of direct torque controlled induction motor drives. IEEE T. Power Electr., 21(4): 1041-1052.

Kuo-Kai, S., L. Juu-Kuh, P. Van-Truong, Y. Ming-Ji and W. Te-Wei, 2010. Global minimum torque ripple design for direct torque control of induction motor drives. IEEE T. Ind. Electron., 57(9): 31483156.

Kyo-Beum, L. and F. Blaabjerg, 2007. An improved DTC-SVM method for sensorless matrix converter drives using an over modulation strategy and a simple nonlinearity compensation. IEEE T. Ind. Electron., 54(6): 3155-3166.

Lascu, C., I. Boldea and F. Blaabjerg, 2004. Direct torque control of sensorless induction motor drives: a sliding-mode approach. IEEE T. Ind. Appl., 40(2): 582-590.

Mabrouk, J., J. Kamel, K. Yassine and B. Mohamed, 2012. Luenberger state observer for speed sensorless ISFOC induction motor drives. J. Electr. Power Syst. Res., 89: 139-147.

Mohammad, V.K., S.Y. Ahmad and M.K. Hossein, 2010. Direct power control of DFIG based on discrete space vector modulation. J. Renew. Energ., 35(5): 1033-1042.

Monmasson, E. and J. Louis, 2003. Presentation of a control law for IM drive based on the dynamic reconfiguration of a DTC algorithm and a SVMDTC algorithm. Math. Comput. Simul., 63(3): 321333.

Murat, B., B. Seta and G. Metin, 2007. Switching EKF technique for rotor and stator resistance estimation in speed sensorless control of IMs. J. Energ. Convers. Manag., 48(12): 3120-3134.

Panneer Selvam, N., M. Arul Prasanna, I. Gerald, C. Raj and Dr. V. Rajasekaran, 2012. A Novel direct torque controlled IM drives fed from CSI with minimum ripple torque. Int. J. Eng. Trends Technol., 3(4): 507-511. 
Patel, C., R.P.P.A. Day, A. Dey, R. Ramchand, K.K. Gopakumar and M.P. Kazmierkowski, 2012. Fast direct torque control of an open-end induction motor drive using 12-sided polygonal voltage space vectors. IEEE T. Power Electr., 27(1): 400-410.

Raja, S.T. and N.S. Bayindi, 2003. Speed estimation of an induction motor using Elman neural network. J. Neurocomput., 55(3-4): 727-730.

Tripathi, A., A.M. Khambadkone and S.K. Panda, 2006. Dynamic control of torque in overmodulation and in the field weakening region. IEEE T. Power Electr., 21(4): 1091-1098.

Vasudevan, M., R. Arumugam and S. Paramasivam, 2006. Development of torque and flux ripple minimization algorithm for direct torque control of induction motor drive. J. Electr. Eng., 89(1): 41-51.
Yuksel, O. and D. Mehmet, 2011. Speed estimation of vector controlled squirrel cage asynchronous motor with artificial neural networks. J. Energ. Convers. Manag., 52(1) 675-686.

Yuttana, K., P. Suttichai and A.T. Hamid, 2008. Modified direct torque control method for induction motor drives based on amplitude and angle control of stator flux. J. Electr. Pow. Syst. Res., 78(10): 1712-1718.

Zhifeng, Z., T. Renyuan, B. Baodong and X. Dexin, 2010. Novel direct torque control based on space vector modulation with adaptive stator flux observer for induction motors. IEEE T. Magn., 46(8): 3133-3136. 